\title{
Retraction note: Histopathological and clinical evaluation of Kombucha tea and Nitrofurazone on cutaneous full-thickness wounds healing in rats: an experimental study
}

\author{
Fardin Barati ${ }^{1}$, Javad Javanbakht ${ }^{2 *}$, Farajollah Adib-Hashemi ${ }^{1}$, Ehsan Hosseini ${ }^{3}$, Reyhaneh Safaeie ${ }^{4}$, \\ Mojtaba Rajabian ${ }^{5}$, Mostafa Razmjoo ${ }^{6}$, Reza Sedaghat ${ }^{7}$ and Mehdi Aghamohammad Hassan ${ }^{1}$
}

\section{Retraction}

The Editor-in-Chief and Publisher have retracted this article [1] because the scientific integrity of the content cannot be guaranteed. An investigation by the Publisher found it to be one of a group of articles we have identified as showing evidence suggestive of attempts to subvert the peer review and publication system to inappropriately obtain or allocate authorship. This article showed evidence of plagiarism (most notably from the articles cited [2-4]), peer review and authorship manipulation.

\begin{abstract}
Author details
'Department of Clinical Science, Faculty of Veterinary Medicine, Tehran University, Tehran, Iran. ${ }^{2}$ Department of Pathology, Faculty of Veterinary Medicine, Tehran University, Tehran, Iran. ${ }^{3}$ Faculty of Para Veterinary Medicine, Ilam University, Ilam, Iran. ${ }^{4}$ Graduate, Faculty of Veterinary Medicine, Tehran University, Tehran, Iran. ${ }^{5}$ Food Hygiene Department, University of Shahekord, Shahekord, Iran. ${ }^{6}$ Faculty of Veterinary Medicine, Razi University, Kermanshah, Iran. ${ }^{7}$ Department of Pathology, Faculty of Medicine Science, Shahed University, Tehran, Iran.
\end{abstract}

Received: 17 October 2016 Accepted: 19 October 2016

Published online: 02 November 2016

\section{References}

1. Barati F, Javanbakht J, Adib-Hashemi F, Hosseini E, Safaeie R, Rajabian M, Razmjoo M, Sedaghat R, Aghamohammad Hassan M. Histopathological and clinical evaluation of Kombucha tea and Nitrofurazone on cutaneous full-thickness wounds healing in rats: an experimental study. Diagn Pathol. 2013:8:120.

2. Bayat M, Vasheghani MM, Razavie N, Jalili MR. Effects of low-level laser therapy on mast cell number and degranulation in third-degree burns of rats. J Rehabil Res Dev. 2008;45(6):931-8.
3. Kallela L, Desseauxb V, Hamdia M, Stockerb P, Ajandouz EH. Insights into the fermentation biochemistry of Kombucha teas and potential impacts of Kombucha drinking on starch digestion. Food Res Int. 2012;49(1):226-32.

4. Hartmann AM, Burleson LE, Holmes AK, Geist CR. Effects of chronic kombucha ingestion on open-field behaviors, longevity, appetitive behaviors, and organs in c57-bl/6 mice: a pilot study. Nutrition. 2000;16(9):755-61.

* Correspondence: javadjavanbakht@ut.ac.ir

${ }^{2}$ Department of Pathology, Faculty of Veterinary Medicine, Tehran University, Tehran, Iran 